ОЦЕНКА КОГНИТИВНЫХ ФУНКЦИЙ И МЕТАБОЛИЧЕСКИХ ПАРАМЕТРОВ ЗРЕЛЫХ

КРЫС-САМЦОВ ЛИНИИ SPRAGUE-DAWLEY НА ФОНЕ ВЫСОКОКАЛОРИЙНОЙ И ГИПОКАЛОРИЙНОЙ ДИЕТЫ

(с) Е.А. Шестакова ${ }^{*}$, А.В. Ставровская², А.С. Гущина², Н.Г. Ямщикова², А.С. Ольшанский²

'ФГБУ «Национальный медицинский исследовательский центр эндокринологии» Минздрава России, Москва ФГБНУ «Научный центр неврологии», Москва, Россия

Обоснование. Ожирение является фактором риска развития когнитивных расстройств. Однако неясно, приводит ли резкое ограничение калорийности пищи к улучшению когнитивных функций.

Цель. Оценить когнитивные функции и метаболические параметры у крыс-самцов линии Sprague-Dawley на фоне высококалорийной и нормокалорийной (с переходом в гипокалорийную) диет.

Meтоды. Крысы-самцы линии Sprague-Dawley $(\mathrm{n}=32)$ были разделены на 2 группы по 16 особей в каждой: группа «контроль» получала нормокалорийную диету, группа «ожирение»- высококалорийную. Через 90 сут крысы группы «контроль» были переведены на гипокалорийную диету, крысы группы «ожирение» остались на высококалорийном питании. С целью оценки двигательной активности и когнитивных функций в конце исследования (на 180-е сутки) у животных обеих групп проведены поведенческие тесты: «открытое поле», «сужающаяся дорожка», «приподнятый крестообразный лабиринт» (ПКЛ) и условные реакции пассивного избегания (УРПИ). В ходе исследования проведено два глюкозотолерантных теста (ГТТ): исходно и через 30 сут.

Результаты. К концу исследования вес крыс группы «ожирение» значительно превышал вес контрольных животных $(547,69 \pm 11,32$ г против 442,8 19,8 г, p=0,0001). По результатам второго ГТТ крысы контрольной группы имели нормальные показали углеводного обмена, крысы группы «ожирение» - повышение уровня глюкозы в постпрандиальном периоде.

Тестирование в открытом поле показало, что крысы группы «ожирение» более активно перемещались по площади

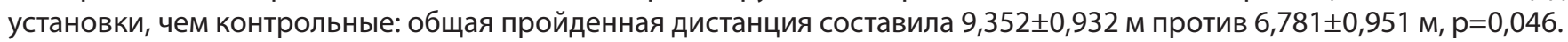

При тестировании на установке «сужающаяся дорожка» число оступаний задними конечностями у крыс с ожирением

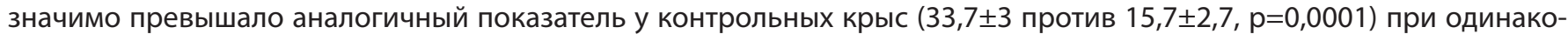
вом времени выполнения теста.

При тестировании в ПКЛ статистически значимых различий по ключевым параметрам теста между группами не выявлено. Однако количество выглядываний из закрытого рукава у животных группы «ожирение» значительно выше, чем у группы «контроль» $(4,19 \pm 0,6$ против $2,30 \pm 0,58, p=0,044)$.

При тестировании воспроизведения УРПИ было показано, что через 1 сут после нанесения болевого раздражения латентный период перехода в темный отсек у крыс группы «ожирение» был значимо больше, чем у контрольных $(180,0 \pm 0,0$ против $128,86 \pm 21,45, p=0,008)$. Это свидетельствует о лучшем сохранении памятного следа по сравнению с «контрольными» крысами.

К концу исследования 30\% животных на гипокалорийной диете погибли.

Заключение. Крысы, получавшие высококалорийную диету, были более подвижны, менее тревожны и обладали лучшей способностью к обучению, чем животные на гипокалорийном питании. Длительное следование гипокалорийной диете может негативно сказываться на когнитивных функциях.

КЛЮЧЕВЫЕ СЛОВА: ожирение, когнитивные расстройства, голод, диета, крысы.

\title{
COGNITIVE FUNCTION AND METABOLIC FEATURES IN MALE SPRAGUE-DAWLEY RATS RECEIVING HIGH-FAT AND LOW-CALORIE DIETS
}

(c) Ekaterina A. Shestakova ${ }^{*}$, Alla V. Stavrovskaya ${ }^{2}$, Anastasiya S. Gushchina², Nina G. Yamshikova², Artyom S. Olshansky²

'Endocrinology Research Centre, Moscow, Russia

${ }^{2}$ Research Center of Neurology, Moscow, Russia

Background: Obesity is a risk factor for cognitive disorders. However, it is still unknown whether low-calorie diet will improve cognitive function in obese patients.

Aim: To evaluate cognitive function and metabolic features in male Sprague-Dawley rats receiving high-fat and low-calorie diets.

Materials and methods: The work was carried out on Sprague Dawley male rats $(n=32)$, which were divided into 2 groups with 16 animals in each group: Control (normal / low-calorie diet) and Obesity (high-fat diet). In 90 days the rats of the Control group were transferred to a low-calorie diet, the rats of the Obesity group continued to receive high-fat diet. To assess motor activity and cognitive functions at the end of the study (180 days), following behavioral tests were conducted: "open 
field", "tapering beam", "elevated plus-maze" (EPM) and "passive avoidance reaction". During the study glucose tolerance test were performed: at baseline (GTT 1) and in 30 days (GTT 2).

Results: Obesity group rats gained weight significantly faster than the control animals (547.69 $\pm 11.32 \mathrm{~g}$ against $442.8 \pm 19.8$ $g$ at study end, $p=0.0001)$. GTT 2 showed normal carbohydrate metabolism in control group, postprandial hyperglycemia in obesity group. Testing in the open field showed that the rats of the obesity group moved more actively across the installation area than the control ones: the total distance covered was $9.352 \pm 0.932 \mathrm{~m}$ against $6.781 \pm 0.951 \mathrm{~m}, \mathrm{p}=0.046$.

The results of a tapering beam test showed that the number of hind limb extrusions in obese rats significantly exceeded this parameter in control group ( $33.7 \pm 3$ vs. $15.7 \pm 2.7, p=0.0001)$, test time in both groups did not differ.

When testing in EPM, there was no significant difference in any of the key test parameters between the groups. However, the number of looking out from the closed arms in animals of the obesity group was significantly higher than in the control group ( $4.19 \pm 0.6$ vs. $2.30 \pm 0.58, p=0.044)$. When testing the reproduction of conditional reactions of passive avoidance it was shown that after day 1 of the pain stimulation application the latent period of transition to the dark compartment in the obesity group was significantly higher than that of the control group (180.0 \pm 0.0 vs. $12886 \pm 21.45, p=0.008)$. This indicates a better preservation of the memorial trail compared to the "control" rats. By the end of the study $30 \%$ of animals in the control group died.

Conclusions: Rats on high-fat diet were more active, less anxious and showed better results in training tests comparing to animals on low-calorie diet. Adherence to low-calorie diet may be harmful for cognitive functions.

KEYWORDS: obesity, cognitive disorders, starvation, diet, rat.

\section{ОБОСНОВАНИЕ}

Основной демографической тенденцией современного общества является старение населения. С 1926 до 2018 гг. в РФ численность населения старше 65 лет возросла с 4,2\% до 14,6\% [1]. По мере увеличения средней продолжительности жизни растет распространенность и когнитивных расстройств [2].

Второй и не менее социально значимой проблемой здравоохранения является рост заболеваемости ожирением и сахарным диабетом (СД) 2 типа. По данным ВОЗ, в 2016 г. более 1,9 млрд взрослых старше 18 лет имели избыточный вес, из них свыше 650 млн страдали ожирением [3]. К 2045 г., по оценке Международной диабетической федерации (IDF), ожидается 629 млн пациентов с СД [4].

Наличие ожирения еще более усугубляет нарушение когнитивных функций. Так, ожирение и СД 2 типа в среднем возрасте являются факторами риска развития деменции $[5,6]$. Таким образом, растущая заболеваемость ожирением приведет к усугублению проблемы когнитивных расстройств у стареющего населения планеты.

Высокая распространенность ожирения и СД 2 типа на первый план выводит необходимость разработки эффективных мер профилактики и лечения данных состояний. Согласно большинству рекомендаций, целью лечения ожирения является снижение массы тела в первую очередь за счет ограничения рациона питания [7, 8]. Несмотря на то что под ограничением калорийности питания в рекомендациях подразумевается соблюдение умеренно гипокалорийного питания, ряд исследований указывает на эффективность использования сверхгипокалорийной диеты для более быстрого снижения массы тела и достижения ремиссии СД 2 типа [9]. Однако остается неясным, приводит ли столь резкое ограничение калорийности питания к улучшению когнитивных функций.

В нашем исследовании мы ставили целью сопоставить результаты выполнения когнитивных тестов у крыс-самцов линии Sprague-Dawley на фоне высококалорийной и нормо/гипокалорийной диеты. При этом переход от нормо- к гипокалорийному питанию расценивался как стрессовый фактор, влияющий на выполнение когнитивных тестов. Отличительной особенностью данного исследования стало длительное наблюдение за животными от ювенильного до взрослого этапа (в течение 180 дней).

\section{ЦЕЛЬ}

Оценить когнитивные функции и метаболические параметры у крыс-самцов линии Sprague-Dawley на фоне высококалорийной и нормокалорийной (с переходом в гипокалорийную) диет.

\section{МЕТОДЫ}

\section{Дизайн исследования}

Исследование являлось интервенционным одноцентровым проспективным контролируемым нерандомизированным.

Работа была проведена на крысах-самцах линии Sprague Dawley, полученных из питомника лабораторных животных «Пущино» в возрасте 2,5-3 мес. Животные содержались в виварии института по 5-6 голов в клетках (каркас из поликарбоната 480×375×210 мм 1500U001, крышка клетки из нержавеющей стали 1400U116). В качестве подстила в клетках использовался материал REHOFIX (Rettenmaier \& Sohne, Germany), а также подстилочный материал из лиственных пород деревьев, стружка обеспыленная мелкая в соответствии с нормами размещения. Подстилочный материал исследован на микробиологические показатели, пестициды (хлор) и токсичные элементы (свинец, кадмий, ртуть, мышьяк). Животные содержались при температуре воздуха в виварии 21-24 $\mathrm{C}$, относительной влажности - 30-70\%, световом режиме - 12:12 ч. Определяемый датчиком диапазон значений концентрации летучих веществ (аммиак, оксид углерода) - 0,4-1 мг/м³. Животные обеспечивались кормом в соответствии с условиями эксперимента.

В течение первых 14 сут животные находились в условиях карантина. В этот период осуществлялись ежедневный внешний осмотр и оценка состояния животных. Животные с обнаруженными в ходе осмотра отклонениями в экспериментальные группы не включались.

При формировании экспериментальных групп каждому животному был присвоен индивидуальный номер, обозначенный на хвосте нетоксичным красителем. Нумерация животных проводилась от 1 до 32. На карточ- 


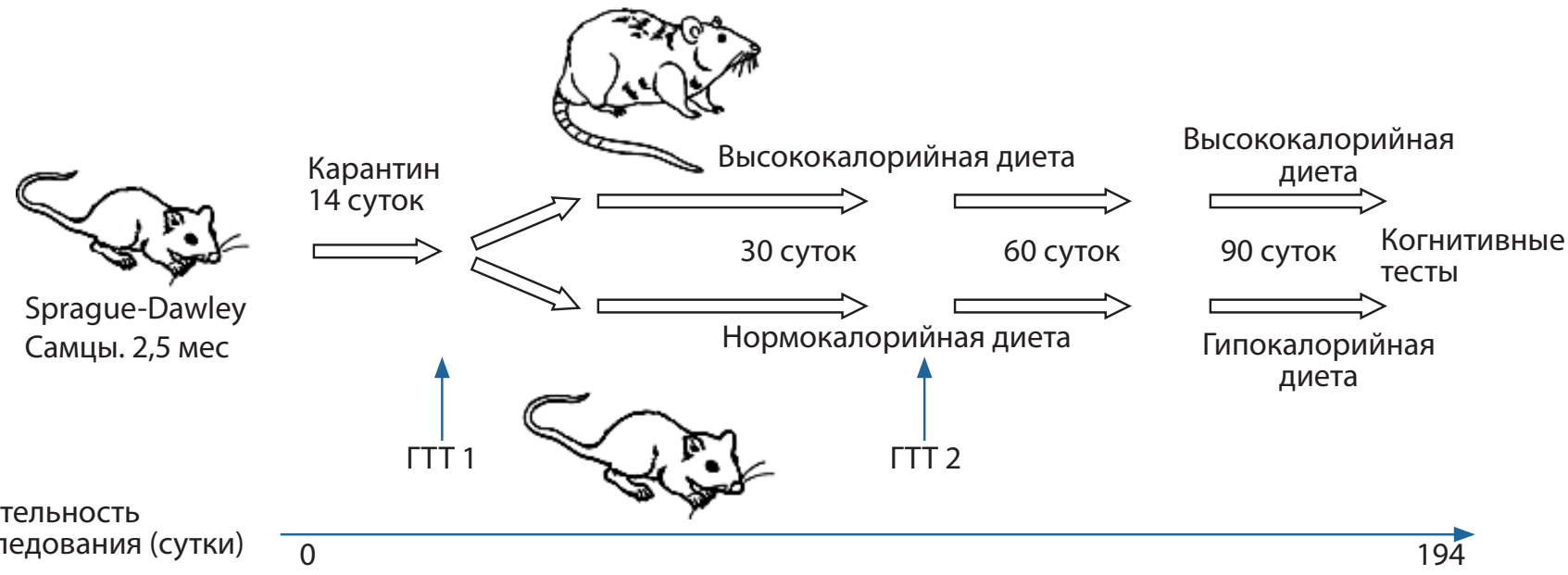

Рис. 1. Дизайн исследования.

Примечания: ГТТ - глюкозотолерантный тест

ке клетки, в которой содержатся животные, была указана следующая информация: номера животных и название группы («контроль» (нормо/гипокалорийная диета) и «ожирение» (высококалорийная диета)). Во время карантина все животные получали нормокалорийное питание. По окончании карантина был проведен первый глюкозотолерантный тест (ГТТ 1), после чего группа «контроль» стала получать нормокалорийную диету, группа «ожирение» - высококалорийную. Через 30 сут проведен второй ГТТ (ГТТ 2). Далее в течение 60 сут животные получали корм различной калорийности в соответствии с группой. Впоследствии крысы группы «контроль» были переведены на гипокалорийную диету, крысы группы «ожирение» получали высококалорийную диету в течение еще 90 сут. По окончании наблюдения (через 180 сут) животным обеих групп были проведены тесты на когнитивные функции.

Животные содержались в соответствии с правилами, принятыми Европейской конвенцией по защите позвоночных животных, используемых для экспериментальных и иных научных целей (Страсбург, 1986).

Дизайн исследования представлен на рисунке 1.

\section{Условия проведения}

Исследование проведено в Лаборатории экспериментальной патологии нервной системы Федерального государственного бюджетного научного учреждения «Научный центр неврологии».

\section{Продолжительность исследования}

Крысы были адаптированы в виварии в отдельном помещении в течение 14 сут до начала эксперимента. Далее животные были разделены на группы «контроль» и «ожирение», после чего наблюдались в течение 180 сут. Группа «контроль» через 90 сут после окончания карантина была переведена с нормо- на гипокалорийную диету. Суммарная продолжительность исследования составила 194 сут.

\section{Описание медицинского вмешательства}

По окончании карантина животные были поделены на 2 группы. Животным первой группы («контроль») была назначена диета, включающая только полнорационный комбикорм для содержания лабораторных животных производства ООО «Лабораторкорм», из расчета
6 г на 100 г веса животного в сутки. Животные второй группы («ожирение»), помимо комбикорма, в том же количестве, что и животные первой группы, ежедневно получали обогащение рациона. В данной работе использовалось несколько вариантов обогащенной диеты, ввиду того, что животные на определенном этапе отказывались употреблять предлагаемую им кормосмесь.

Первый вариант обогащения состоял из кормосмеси, содержащей 10 г белков, 60 г жиров, 134 г углеводов на 200 г смеси, которую животные опытной группы получали в сутки. Дополнительно животные получали 10\% раствор фруктозы в качестве питья.

Второй вариант обогащенного рациона представлял собой кормосмесь, содержащую белков - 18 г; жиров 95 г; углеводов - 105 г на 380 г, которую опытная группа крыс получала в сутки. Питье - фильтрованная вода.

Третий вариант обогащения по углеводам и жирам представлял собой кормосмесь, содержащую белков 18,54 г, жиров - 97,05 г, углеводов - 132,72 г на 330 г, которую опытная группа крыс получала в сутки. Питье - фильтрованная вода.

Продолжительность применения каждого обогащения составляла 30-35 дней, рационы чередовались с 1-го по 3-й дважды.

Животным обеих групп был проведен глюкозотолерантный тест сразу после окончания карантина (ГТТ 1) и через 30 суток после его окончания (ГТТ 2).

Через 90 сут после окончания карантина животные группы «контроль» были переведены на гипокалорийное питание. В нашем случае оно достигалось уменьшением количества корма с 6 до 4 г на 100 г веса животных (то есть на 33,3\%). В группе «ожирение» количество комбикорма не изменялось.

\section{Основной исход исследования}

С целью оценки двигательной активности и когнитивных функций в конце исследования (на 180-е сутки) уживотных обеих групп проведены следующие поведенческие тесты: «открытое поле», «сужающаяся дорожка», «приподнятый крестообразный лабиринт» и «УРПИ».

Дополнительные исходы исследования

В обеих группах проводилась оценка состояния углеводного обмена в ходе ГТТ 1 и ГТТ 2. 


\section{Методы регистрации исходов}

Установка для изучения изменения двигательной активности и ориентировочно-исследовательского поведения «открытое поле» представляла собой квадратный короб со стороной 75 см, высотой стенок $40 \mathrm{~cm}$, пол которого был разделен на 25 равных квадратов. В течение 3 минут осуществляли фиксирование поведения и последующий анализ данных с помощью системы видеонаблюдения Any-maze с программным обеспечением.

Установка для изучения двигательных нарушений «сужающаяся дорожка» представляла собой планку длиной 150 см, толщиной 2 см, равномерно сужающуюся по ширине от 9 см на одном конце до 5 см на противоположном. Поверх данной планки располагалась другая, меньшего размера, конгруэнтная первой. Таким образом, по всей длине нижней планки, с обеих сторон образовывались узкие (1,5 см) дорожки. К узкому концу «дорожки» был прикреплен короб (укрытие), 25×19×12, имеющий съемную крышку и отверстие в передней панели, через которое животное могло проникнуть внутрь. Пол короба был покрыт опилками. Вся конструкция была приподнята над полом на высоту 70 см. Экспериментальное животное должно было пройти по верхней планке от начала дорожки до укрытия. Подсчитывалось число оступаний передними и задними конечностями при проходе по всей длине дорожки и время выполнения теста.

Изучение изменений когнитивных функций и эмоционального состояния экспериментальных крыс проводили с помощью теста УРПИ. Воспроизведение пассивных оборонительных реакций оценивали по величине латентного периода (ЛП) перехода крыс из ярко освещенного (большего по размеру) отсека камеры в темный (меньший) отсек. В первый день эксперимента проводили приучение крыс к установке, помещая их в светлый отсек камеры, и регистрировали ЛП перехода в темный отсек. На следующий день процедуру повторяли. Однако после перемещения в темный отсек животным наносилось неизбегаемое болевое воздействие (нанесение удара постоянным электрическим током (0,2 мА, 3 с) через металлический решетчатый пол). Такое воздействие применялось однократно. На 1, 3 и 7-е сутки после предъявления электрического раздражения экспериментальные животные помещались в установку для оценки воспроизведения условных реакций. Если крыса не переходила в темный отсек в течение 3 минут, тест прекращали и помещали животное в домашнюю клетку.

Для оценки уровня тревожности крыс использовались крестообразный лабиринт, приподнятый над полом на 75 см, два рукава которого (один напротив другого) имели боковые и торцевые стенки высотой 40 см («закрытые рукава», 3Р), два рукава стенок не имели («открытые рукава», ОР). Ширина рукавов - 15 см, длина 50 см, на их пересечении располагался стартовый отсек (площадка размером 15×15 см). В начале эксперимента крыса помещалась в центр пересечения рукавов, учитывалось время, проведенное в ОР и ЗР, пройденная в них дистанция и число выглядываний из ЗР. Продолжительность теста - 3 минуты.

Во время ГТТ раствор глюкозы вводили внутрибрюшинно в дозе 1,5 мг/ кг после 8-10 часовой пище- вой и питьевой депривации. Измерение уровня сахара в крови животных проводили с помощью глюкометра «Сателлит экспресс» до введения глюкозы и спустя 10, 30, 60 и 120 минут. Во время проведения каждого ГТТ осуществляли забор крови из хвостовой вены крыс. Для ограничения подвижности животным вводили золетил 100 в дозе 13 мг/кг и размещали их в индивидуальных пеналах.

\section{Этическая экспертиза}

Исследование было проведено в соответствии с правилами, принятыми Европейской конвенцией по защите позвоночных животных (Страсбург, 1986); Приказом М3 РФ № 119 Н от 1 апреля 2016 г. «Об утверждении Правил лабораторной практики», Principles of Good Laboratory Practice (OECD, ENV/ MC/ CUEM (98)17, 1997); ГОСТ 330442014 «Принципы надлежащей лабораторной практики» (идентичен GLP OECD); со статьей 11 Федерального закона от 12 апреля 2010 г. № 61-Ф3 «О6 обращении лекарственных средств» (ред. от 22.10.2014).

\section{Статистический анализ}

Размер выборки предварительно не рассчитывался. Полученные в результате ГТТ и поведенческих экспериментов данные обрабатывали в программе IBM SPSS Statistics, используя однофакторный дисперсионный анализ (ANOVA) с последующим меж- и внутригрупповым апостериорным сравнением по критерию Фишера.

Результаты представлены в виде среднего и стандарт-

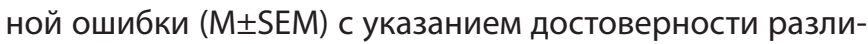
чий между сравниваемыми группами по изучаемым показателям. Статистически значимыми считали различия при $\mathrm{p}<0,05$.

\section{РЕЗУЛЬТАТЫ}

Объекты (участники) исследования

Лабораторные животные ( $n=32)$ были разделены на две группы по 16 особей в каждой.

В результате обогащенного питания крысы опытной группы значительно опережали контрольных животных в прибавке в весе (рис. 2). К концу эксперимента вес отдельных животных на высококалорийной диете превышал 650 г. Внешне животные выглядели хорошо, имели блестящий шерстный покров, у них не наблюдалось выделений из глаз и носа, живо реагировали на внешние стимулы, не проявляли агрессии ни к другим животным в клетке, ни к экспериментаторам. У крыс группы «контроль» при переходе на гипокалорийную диету замедлился процесс набора веса и удерживался на одном уровне до завершения эксперимента.

\section{Основные результаты исследования}

\section{1. Тест «открытое поле»}

Тестирование в открытом поле выявило различия в величине пройденной дистанции между двумя группами. Крысы группы «ожирение» более активно перемещались по площади установки, чем контрольные: общая пройденная дистанция составила 9,352士0,932 м против $6,781 \pm 0,951 \mathrm{~m}, \mathrm{p}=0,046$. 


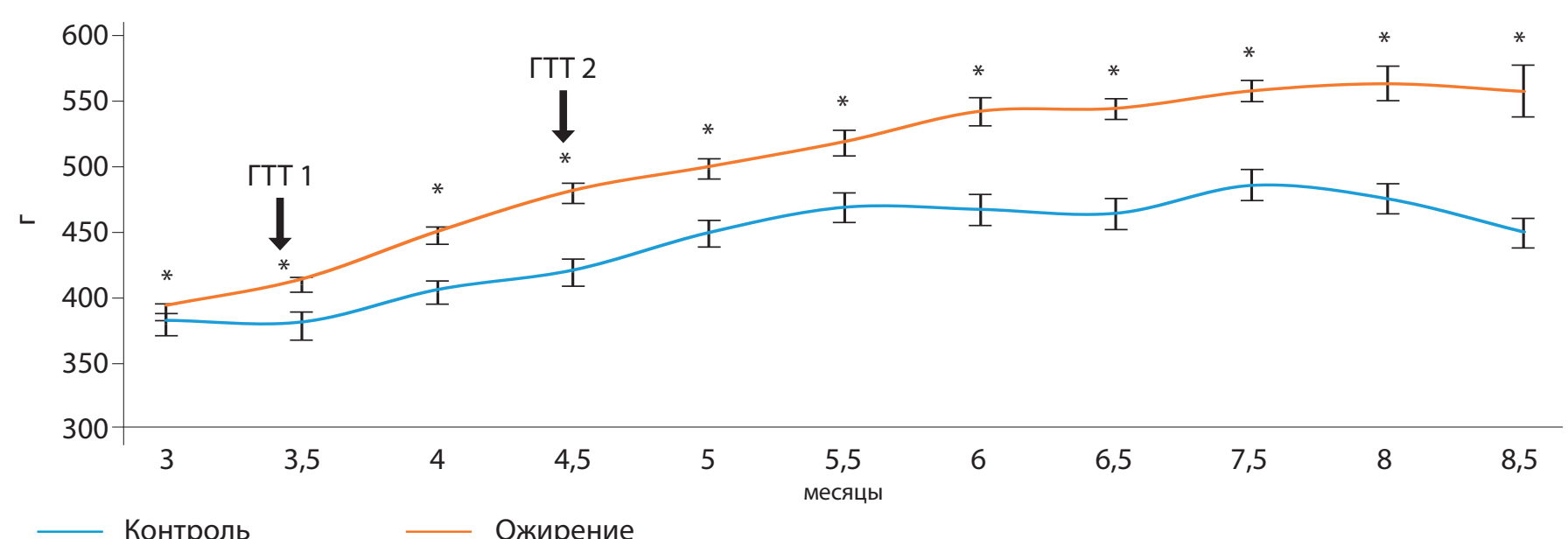

Рис. 2. Динамика изменения веса экспериментальных животных.

Примечания: По оси ординат: вес в граммах; по оси абсцисс: месяцы эксперимента; * - различия статистически значимы при р $\leq 0,05$ ( $p=0,440 ; 0,018$; 0,002; 0,0001; 0,001;0,002; 0,0001 последние 5 точек)

\section{2. Тест «сужающаяся дорожка»}

При тестировании на установке «сужающаяся дорожка» было показано, что у крыс группы «контроль» нет различий между количеством оступаний передними и задними ко-

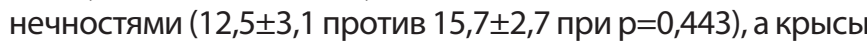
группы «ожирение» чаще оступались задними конечностя-

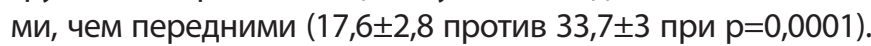
Кроме этого, число оступаний задними конечностями у крыс с ожирением значимо превышает аналогичный показатель у контрольных крыс (табл. 1). При этом время выполнения теста у крыс обеих групп не различалось.

Результаты теста «сужающаяся дорожка» представлены в таблице 1.

\section{3. Тест «приподнятый крестообразный лабиринт»}

При тестировании в приподнятом крестообразном лабиринте было показано, что животные обеих групп перемещались по рукавам лабиринта и проводили там примерно одинаковое количество времени. По ключевым параметрам теста статистически значимых различий между группами не выявлено (табл. 2).

Следует отметить, что количество выглядываний из ЗР на открытые лучи (эпизоды, когда крыса осматривала открытые лучи, но опиралась на них только передними лапами) у животных группы «ожирение» значительно выше, чем у группы «контроль» $(4,19 \pm 0,6$ против $2,30 \pm 0,58$ соответственно, $p=0,044)$. Увеличение этого показателя свидетельствует об уменьшении уровня тревожности у животных, получавших высококалорийную диету.

\section{4. Тест «условный рефлекс пассивного избегания»}

В тесте УРПИ животное должно обучиться не заходить в темную камеру, где оно получило болевое раздраже-

Таблица 1. Результаты прохождения теста «сужающаяся дорожка»

\begin{tabular}{|c|c|c|c|}
\hline & $\begin{array}{c}\text { Группа } \\
\text { «контроль» }\end{array}$ & $\begin{array}{c}\text { Группа } \\
\text { «ожирение» }\end{array}$ & $\begin{array}{l}\text { Различия между } \\
\text { группами }\end{array}$ \\
\hline $\begin{array}{l}\text { Количество оступаний по всей длине дорожки задними } \\
\text { лапами, \% от общего количества шагов }\end{array}$ & $15,7 \pm 2,7$ & $33,7 \pm 3^{*}$ & $p=0,0001$ \\
\hline $\begin{array}{l}\text { Количество оступаний по всей длине дорожки передними } \\
\text { лапами, \% от общего количества шагов }\end{array}$ & $12,5 \pm 3,1$ & $17,6 \pm 2,8$ & $p=0,189$ \\
\hline Время выполнения теста, с & $11,75 \pm 1,06$ & $13,75 \pm 0,91$ & $p=0,260$ \\
\hline
\end{tabular}

Примечания: *- по сравнению с группой «Контроль»

Таблица 2. Результаты теста «приподнятый крестообразный лабиринт».

\begin{tabular}{|c|c|c|c|}
\hline & $\begin{array}{c}\text { Группа } \\
\text { «контроль» }\end{array}$ & $\begin{array}{c}\text { Группа } \\
\text { «ожирение» }\end{array}$ & $\begin{array}{c}\text { Различия между } \\
\text { группами }\end{array}$ \\
\hline Общая пройденная дистанция, м & $2,145 \pm 0,541$ & $2,7324 \pm 0,442$ & $p>0,05$ \\
\hline Количество выходов в ОР & $0,80 \pm 0,36$ & $1,63 \pm 0,53$ & $p>0,05$ \\
\hline Время, проведенное в ОР, с & $8,49 \pm 5,53$ & $10,81 \pm 4,04$ & $p>0,05$ \\
\hline Дистанция, пройденная в ОР, м & $0,101 \pm 0,079$ & $0,184 \pm 0,0907$ & $p>0,05$ \\
\hline Количество заходов в ЗР & $2,80 \pm 0,83$ & $3,94 \pm 0,52$ & $p>0,05$ \\
\hline Время, проведенное в 3Р, с & $154,22 \pm 15,51$ & $158,74 \pm 5,30$ & $p>0,05$ \\
\hline Дистанция, пройденная в ЗР, м & $1,823 \pm 0,516$ & $2,1954 \pm 0,3661$ & $p>0,05$ \\
\hline
\end{tabular}

Примечания: ОР - открытые рукава; ЗР - закрытые рукава. 


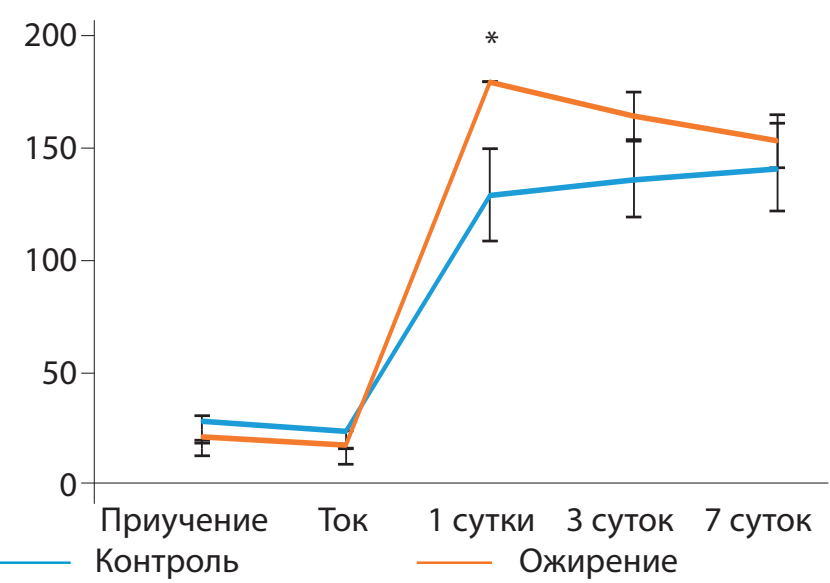

Рис. 3. Латентный период перехода из светлого отсека камеры УРПИ в темный.

Примечания: по оси ординат: время (с); по оси абсцисс: дни эксперимента. * - различия статистически значимы между группами при $\mathrm{p}=0,008$

ние, и пассивно избегать неприятной ситуации, находясь в светлом отсеке. Проверка сохранения УРПИ (воспроизведения рефлекса) состоит в повторном помещении животного в освещенный отсек и т.д. через различные интервалы времени. В нашем эксперименте было показано, что через сутки после нанесения неизбегаемого удара током ЛП перехода в темный отсек камеры у крыс группы «контроль» составил около 130 с, тогда как у крыс группы «ожирение» - 180 с, т.е. все животные данной группы оставались в светлом отсеке, что свидетельствует о более прочном условном рефлексе. При последующих тестированиях, через 3 и 7 сут, величина ЛП перехода у «контрольных» крыс практически не изменялась, а у крыс группы «ожирение» снижалась, что свидетельствует о более устойчивом эмоциональном состоянии этих животных с меньшим уровнем тревожности по сравнению с «контрольными» крысами (рис. 3).

Таким образом, результаты тестов, позволяющих оценить когнитивные функции и эмоциональное состояние, свидетельствуют, что крысы группы «ожирение» менее тревожны и обладают лучшей способностью к обучению, чем животные группы «контроль».

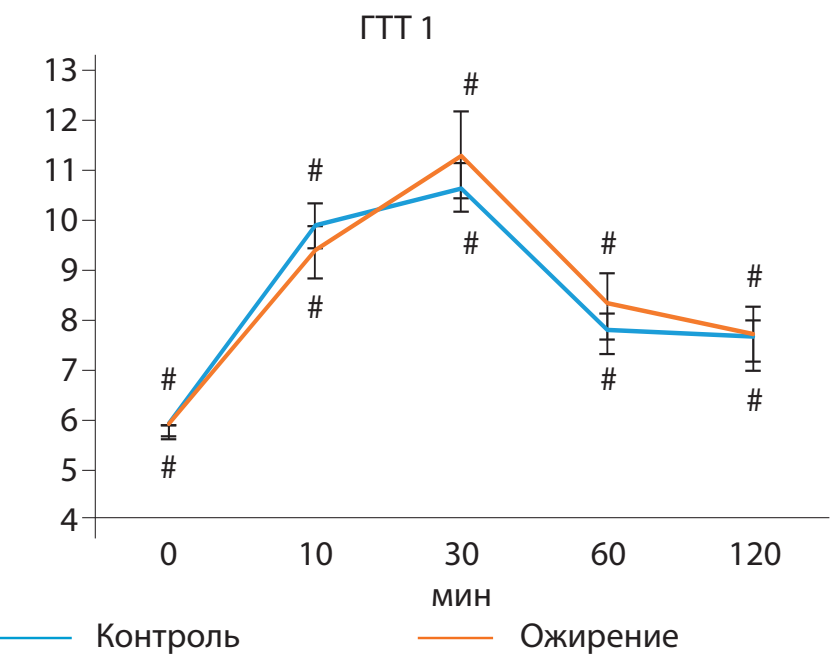

Рис. 4. Результаты глюкозотолерантного теста 1 до начала диеты. Примечания: по оси ординат: концентрация глюкозы (ммоль/л), по оси абсцисс: «0 мин» - до введения глюкозы, остальные точки соответствуют промежуткам времени после внутрибрюшинного введения глюкозы. \# - значимые различия по сравнению с точкой «0 мин» при $\mathrm{p} \leq 0,023$ у группы «контроль» и $p \leq 0,037$ у группы «ожирение»
Дополнительные результаты исследования

За все время эксперимента дважды был проведен ГТТ. ГТТ 1 проводили после окончания карантина до начала предъявления обогащенного рациона, ГТТ 2 - спустя 30 дней после начала диеты соответственно.

Первый ГТТ, проведенный до начала диеты, соответствовал критериям нормального углеводного обмена и не показал различий между группами (рис. 4).

Через 30 дней после начала применения высококалорийного питания у крыс группы «ожирение» отмечалась выраженная гипергликемия в постпрандиальный период (рис. 5). У группы «контроль» сохранялись нормальные показатели гликемии.

\section{Нежелательные явления}

Часть животных контрольной группы (30\%) значительно потеряли в весе, ослабли и погибли от бактериальной инфекции. Кроме этого, крысы проявляли постоянную агрессию к соседям по клетке, имели поредевший шерстный покров, порфириновые выделения из ноздрей.

\section{ОБСУЖДЕНИЕ}

\section{Резюме основного результата исследования}

В ходе эксперимента были отмечены прогрессивное увеличение массы тела и нарушения углеводного обмена у крыс, получающих высококалорийное питание. Однако до конца эксперимента они сохраняли здоровый вид, и численность их группы не изменилась, в отличие от группы, перешедшей на гипокалорийное питание. Тестирование поведения показало также, что крысы, получающие обогащенный рацион, более активны в «открытом поле», менее тревожны и лучше обучаются по сравнению с животными с ограничением калорийности питания.

Обсуждение основного результата исследования

Главной тенденцией последних десятилетий, по данным BO3, является рост заболеваемости неинфекцион-

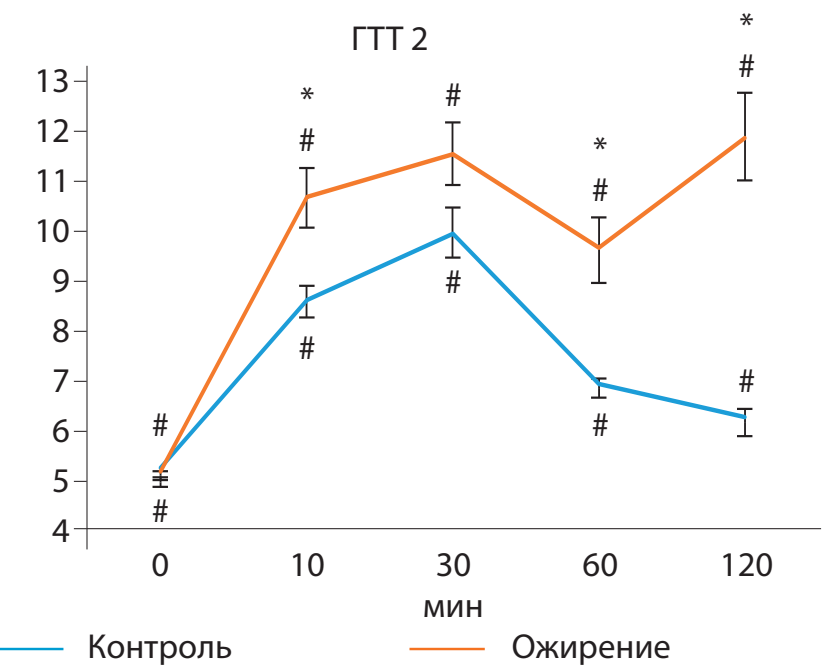

Рис. 5. Результаты глюкозотолерантного теста 2 через 30 дней после начала диеты.

Примечания: \# - статистически значимые различия по сравнению с точкой «0» при $\mathrm{p} \leq 0,018 ;$ * - значимые различия между группами при $p \leq 0,008$ (в точке «10 мин» $p=0,008 ;$ в точке « 60 мин» $p=0,003 ;$ в точке

«120 мин» $p=0,0001)$. Остальные обозначения, как на рис. 4 
ными патологиями, к которым относятся как ожирение, так и когнитивные расстройства $[10,11]$. Обе патологии взаимно отягощают друг друга.

Целью лечения ожирения является снижение массы тела для профилактики развития его осложнений. Несмотря на то что рекомендуемым темпом снижения веса является потеря 5-10\% от исходной массы тела в течение полугода [12], часть исследований демонстрирует эффективность сверхгипокалорийной диеты как в лечении ожирения, так и в достижении ремиссии нарушений углеводного обмена.

Учитывая то, что ожирение является фактором риска развития когнитивных расстройств, то ожидаемым результатом снижения массы тела является улучшение когнитивных функций. Одним из ярких примеров питания с нейропротективным действием является средиземноморская диета, которая отличается большим потреблением злаков, фруктов, овощей, бобовых и оливкового масла, умеренным употреблением молочных продуктов и алкоголя и низким потреблением мяса [13]. Приверженность средиземноморской диете позволяла пациентам лучше проходить когнитивные тесты по сравнению с ограничением калорийности питания без уточнения потребляемых продуктов [14].

Однако с целью снижения веса пациенты часто используют методы более резкого ограничения калорийности питания. В нашем исследовании рацион питания контрольной группы был урезан на 33,3\% по сравнению с исходным, начиная с 90-х суток эксперимента.

Во многих исследованиях на лабораторных животных голод является моделью стрессового фактора. С учетом длительности гипокалорийной диеты в нашем исследовании (3 мес), крысы контрольной группы находились в хроническом стрессе на момент выполнения когнитивных тестов.

По результатам нашего исследования столь длительное воздействие стрессового фактора - голода - негативно сказалось на способности крыс к обучению. Это согласуется с результатами ряда других исследований [15].

В то же время избыточный вес и ожирение также приводят к снижению когнитивных функций. Так, в обзоре, посвященном оценке умственных функций у людей с ожирением, было показано, что избыточный вес приводит к нарушению всех видов умственной деятельности, таких как внимание, вербальная и визуальная память, принятие решений [16].

В нашем исследовании мы проводили сравнительную оценку высоко- и гипокалорийной диет на когнитивные функции, таким образом пытаясь ответить на вопрос, что более губительно для умственных способностей - стабильно высокая масса тела или похудение за счет резкого ограничения калорийности питания. Полученные нами результаты говорят о том, что хроническое следование гипокалорийной диете более негативно воздействует на способность животных к обучению по сравнению с поддержанием высококалорийного рациона.

Одно из исследований, проведенных на самках крыс линии Wistar, на первый взгляд, противоречит полученным в нашем исследовании данным [17]. В данной работе крысы были разделены на 4 группы: получающие нормокалорийное питание; нормокалорийное питание + воздействие стрессового фактора на протяжении
50 дней; высококалорийное питание; высококалорийное питание + стресс. Животные, получающие нормои высококалорийное питание и подвергшиеся воздействию стресса, демонстрировали лучшее выполнение тестов на узнавание новых предметов по сравнению с крысами на высококалорийной диете без стрессовых вмешательств.

Данное исследование по нескольким параметрам отличается от нашего. Во-первых, в данном исследовании стрессовым фактором был не голод. Во-вторых, исследование проведено на самках. Повышенный уровень эстрогенов у самок может приводить к улучшению выполнения когнитивных тестов [18]. Поэтому если у самцов, входивших в наше исследование, воздействие хронического стресса приводило к ухудшению выполнения когнитивных тестов, то у самок наблюдается обратная картина.

Еще одно исследование по сравнению влияния гипои высококалорийных диет на когнитивные функции было проведено на мышах [19]. У самок мышей ограничение калорийности рациона на 20\% приводило к улучшению выполнения тестов на обучаемость, тогда как самцы демонстрировали лучшие результаты в условиях диеты с высоким содержанием углеводов и низким содержанием белка.

Особенностью нашего исследования было моделирование длительного периода голодания у животных (с возраста от 6 мес до 9 мес при средней продолжительности жизни животных до 2 лет). Столь долгое ограничение калорийности рациона у крыс-самцов приводило к более выраженной агрессии и более низкой обучаемости.

Сравнительные исследования влияния высокои низкокалорийных диет проводились и у людей. Некоторые работы говорят о том, что кратковременное следование гипокалорийной диете может быть эффективно в поддержании когнитивных функций. На фоне 6-месячного ограничения калорийности питания вплоть до 890 ккал/сут у людей не отмечалось ухудшения выполнения когнитивных тестов по сравнению с менее строгой диетой или ее отсутствием [20]. Однако это исследование, скорее, можно отнести к оценке кратковременного соблюдения диеты.

В работах, посвященных более длительным периодам голодания у людей, результаты оценки когнитивных функций сопоставимы с нашими результатами. Моделью многолетнего резкого ограничения калорийности рациона могут являться пациенты с неврогенной анорексией: большинство таких больных демонстрировали худшее выполнение когнитивных тестов по сравнению с контрольной группой пациентов с униполярными аффективными расстройствами [21]. Также при наблюдении за здоровыми лицами было выявлено, что снижение массы тела ассоциировалось с более высоким риском развития деменции, чем поддержание стабильной массы тела [22].

Таким образом, в нашем исследовании на крысах линии Sprague-Dawley было выявлено, что длительное потребление рациона с резким ограничением калорийности снижает когнитивные функции животных в большей мере, чем при соблюдении высококалорийной диеты. Эти данные подчеркивают небезопасность длительного следования низкокалорийным диетам. 


\section{Ограничения исследования}

Все экспериментальные животные, в том числе получавшие нормокалорийное питание с последующим переходом на гипокалорийное, размещались в клетке по 5 особей. Корм предъявлялся один раз в сутки в полном объеме. В связи с малым количеством корма крысы группы «контроль» испытывали дополнительный стресс при его дележе. В исследовании когнитивных функций не изучали сохранение памятного следа на длительных сроках.

\section{ЗАКЛЮЧЕНИЕ}

Гипокалорийное питание является одним из способов быстрого снижения массы тела, однако влияние длительного применения данного метода лечения избыточной массы тела и ожирения на когнитивные функции неясно. В нашем исследовании была проведена оценка когнитивных функций самцов крыс линии Sprague-Dawlеу в условиях длительного приема высококалорийной и гипокалорийной диет с целью сопоставить влияние избыточной массы тела и хронического голодания на умственные способности и эмоциональное состояние животных. Результаты проведенных тестов свидетельствуют о том, что крысы, получавшие высококалорийное питание, менее тревожны и обладают лучшей способностью к обучению, чем животные, находящиеся в постоянном голоде. Длительное следование гипокалорийной диете может негативно сказываться на когнитивных функциях.

\section{ДОПОЛНИТЕЛЬНАЯ ИНФОРМАЦИЯ}

Источник финансирования. Работа выполнена при поддержке Российского научного фонда (проект № 17-15-01435 «Ожирение и сахарный диабет: поиск протективных генетических, гормонально-метаболических и молекулярно-клеточных факторов, препятствующих развитию сахарного диабета у лиц с ожирением») - выполнение лабораторных исследований, а также при частичной поддержке программы Президиума РАН № 44 «Фундаментальные механизмы возрастной нейропластичности и разработка новых подходов к диагностике и лечению возраст-зависимых заболеваний мозга» - содержание и ветеринарное сопровождение лабораторных животных.

Конфликт интересов. Авторы декларируют отсутствие явных и потенциальных конфликтов интересов, связанных с публикацией настоящей статьи.

Участие авторов. Шестакова Е.А. - создание концепции исследования, анализ результатов, написание рукописи; Ставровская А.В. - создание концепции исследования, проведение исследования, анализ результатов, написание рукописи; Гущина А.С. - проведение исследования, ветеринарное сопровождение лабораторных животных; Ямщикова Н.Г. - проведение исследования; Ольшанский А.С. - проведение исследования. Все авторы внесли значимый вклад в проведение исследования и подготовку статьи, прочли и одобрили финальную версию статьи перед публикацией.

Благодарности. Выражаем благодарность Титову Д.С. за техническую помощь.

\section{СПИСОК ЛИТЕРАТУРЫ | REFERENCES}

1. gks.ru [интернет]. Демография [доступ от 03.12.2018]. Доступ по ссылке: http://www.gks.ru/wps/wcm/connect/rosstat_main/rosstat/ ru/statistics/population/demography/

2. Prince M, Wimo A, Guerchet M, Ali G, et al. World Alzheimer Report 2015 - The Global Impact of dementia. An analysis of prevalence, incidence, costs and trends. [Internet]. London: Alzheimer's Disease International (ADI); 2015 [cited 2017 Jan 30]. Available from: https:// www.alz.co.uk/research/WorldAlzheimerReport2015.pdf

3. who.int [интернет]. Ожирение и избыточный вес [доступ от 03.12.2018]. Доступ по ссылке: http://www.who.int/ru/news-room/ fact-sheets/detail/obesity-and-overweight.

4. International Diabetes Federation. IDF Diabetes Atlas, 8th edn. Brussels, Belgium: International Diabetes Federation, 2017. Available from: http://www.diabetesatlas.org. Accessed 13 Nov 2017.

5. Whitmer RA, Gunderson EP, Barrett-Connor E, et al. Obesity in middle age and future risk of dementia: a 27 year longitudinal population based study. BMJ. 2005;330(7504):1360-1362 doi: $10.1136 /$ bmj.38446.466238.E0

6. Остроумова О.Д., Суркова Е.В., Ших Е.В., и др. Когнитивные нарушения у больных сахарным диабетом 2 типа: распространенность, патогенетические механизмы, влияние противодиабетических препаратов // Сахарный диабет. - 2018. T. 21. - №4. - C. 307-318. [Ostroumova OD, Surkova EV, Chikh EV, et al. Cognitive impairment in patients with type 2 diabetes mellitus: prevalence, pathogenetic mechanisms, the effect of antidiabetic drugs. Diabetes mellitus. 2018;21(4):307-318. (In Russ.)] doi: 10.14341/DM9660

7. Дедов И.И., Шестакова М.В., Майоров А.Ю., и др. Алгоритмы специализированной медицинской помощи больным сахарным диабетом. / Под ред. Дедова И.И., Шестаковой М.В., Майорова А.Ю. - 8-й выпуск // Сахарный диабет. - 2017. - Т. 20. - №1S. C. 1-121. [Dedov II, Shestakova MV, Mayorov AY, et al. Standards of specialized diabetes care. Dedov II, Shestakova MV, Mayorov AY, editors. 8th edition. Diabetes mellitus. 2017;20(1S):1-121. (In Russ.)] doi: 10.14341/DM2017158

8. Apovian CM, Aronne LJ, Bessesen DH, et al. Pharmacological Management of Obesity: An Endocrine Society Clinical Prac- tice Guideline. J Clin Endocrinol Metab. 2015;100(2):342-362. doi: 10.1210/jc.2014-3415

9. Steven S, Hollingsworth KG, Al-Mrabeh A, et al. Very Low-Calorie Diet and 6 Months of Weight Stability in Type 2 Diabetes: Pathophysiological Changes in Responders and Nonresponders. Diabetes Care. 2016;39(5):808-815. doi: 10.2337/dc15-1942

10. who.int [интернет]. Неинфекционные заболевания [доступ от 03.12.2018]. Доступ по ссылке: http://www.who.int/ru/newsroom/fact-sheets/detail/noncommunicable-diseases

11. Prince $M$, Bryce $R$, Albanese $E$, et al. The global prevalence of dementia: A systematic review and metaanalysis. Alzheimer's Dement. 2013;9(1):63-75.e2. doi: 10.1016/j.jalz.2012.11.007

12. Дедов И.И., Мельниченко Г.А., Шестакова М.В., и др. Национальные клинические рекомендации по лечению морбидного ожирения у взрослых. 3-ий пересмотр (лечение морбидного ожирения у взрослых) // Ожирение и метаболизм. - 2018. T. 15. - №1. - C. 53-70. [Dedov II, Mel'nichenko GA, Shestakova $M V$, et al. Russian national clinical recommendations for morbid obesity treatment in adults. 3rd revision (Morbid obesity treatment in adults).Obesity and metabolism. 2018;15(1):53-70. (In Russ.)] doi: 10.14341/OMET2018153-70

13. Petersson SD, Philippou E. Mediterranean Diet, Cognitive Function, and Dementia: A Systematic Review of the Evidence. Adv Nutr. 2016;7(5):889-904. doi: 10.3945/an.116.012138

14. Dye L, Boyle NB, Champ C, Lawton C. The relationship between obesity and cognitive health and decline. Proc Nutr Soc. 2017;76(4):443454. doi: 10.1017/S0029665117002014

15. Luine V, Gomez J, Beck K, Bowman R. Sex differences in chronic stress effects on cognition in rodents. Pharmacol Biochem Behav. 2017;152:13-19. doi: 10.1016/j.pbb.2016.08.005

16. Prickett C, Brennan L, Stolwyk R. Examining the relationship between obesity and cognitive function: a systematic literature review. Obes Res Clin Pract. 2015;9(2):93-113. doi: 10.1016/j.orcp.2014.05.001

17. Malafaia G, da Silva WAM, Mendes BO, et al. The Cognitive Function Of Wistar Rats Subjected To Cafeteria Diet And To Chronic Stress. J Obes Eat Disord. 2016;2(1):12. doi: 10.21767/2471-8203.100012 
18. Luine V. Estradiol: Mediator of memories, spine density and cognitive resilience to stress in female rodents. J Steroid Biochem Mol Biol. 2015;160:189-95. doi: 10.1016/j.jsbmb.2015.07.022

19. Wahl D, Solon-Biet SM, Wang Q-P, et al. Comparing the Effects of Low-Protein and High-Carbohydrate Diets and Caloric Restriction on Brain Aging in Mice. Cell Rep. 2018;25(8): 2234-2243. doi: 10.1016/j.celrep.2018.10.070

20. Martin CK, Anton SD, Han H, et al. Examination of cognitive function during six months of calorie restriction: results of a ran- domized controlled trial. Rejuvenation Res. 2007:10(2):179-190. doi: 10.1089/rej.2006.0502

21. Sarrar L, Holzhausen M, Warschburger P, et al. Cognitive Function in Adolescent Patients with Anorexia Nervosa and Unipolar Affective Disorders. Eur Eat Disord Rev. 2016;24(3):232-240. doi: 10.1002/erv.2425

22. Luchsinger JA, Patel B, Tang MX, et al. Measures of adiposity and dementia risk in elderly persons. Arch Neurol. 2007;64(3):392-398. doi: 10.1001/archneur.64.3.392

\section{ИНФОРМАЦИЯ ОБ АВТОРАХ [AUTHORS INFO]}

*Шестакова Екатерина Алексеевна, К.М.Н., В.н.с. [Ekaterina A. Shestakova, PhD, leading research associate]; адрес: 117036, Москва, ул. Дм. Ульянова, д. 11 [address: 11 Dm.Ulyanov street, 117036 Moscow, Russia]; ORCID: http://orcid.org/0000-0001-6612-6851; eLibrary SPIN: 1124-7600; e-mail: katiashestakova@mail.ru

Ставровская Алла Вадимовна, к.б.н., в.н.с. [Alla V. Stavrovskaya, PhD in Biology, leading research associate]; ORCID: https://orcid.org/0000-0002-8689-0934; eLibrary SPIN: 8013-7362; e-mail: stavrovskaya.al@gmail.com. Гущина Анастасия Сергеевна, н.с. [Anastasiya S. Gushchina, research associate]; ORCID: https://orcid.org/0000-0003-3026-0279; eLibrary SPIN: 4017-5024; e-mail: anastaisha-2015@mail.ru. Ямщикова Нина Гавриловна, к.б.н., в.н.с. [Nina G. Yamshikova, PhD in Biology, leading research associate]; ORCID: https://orcid.org/0000-0003-4387-2266; eLibrary SPIN: 9385-5576; e-mail: nyamshikova@yandex.ru.

Ольшанский Артём Сергеевич, к.б.н., с.н.с. [Artyom S. Olshansky, PhD in Biology, senior research associate]; ORCID: https://orcid.org/0000-0002-5696-8032; eLibrary SPIN: 7072-0721; e-mail: olshansky@neurology.ru

\section{ЦИТИРОВАТЬ:}

Шестакова Е.А., Ставровская А.В., Гущина А.С., Ямщикова Н.Г., Ольшанский А.С. Оценка когнитивных функций и метаболических параметров зрелых крыс-самцов линии Sprague-Dawley на фоне высококалорийной и гипокалорийной диеты // Ожирение и метаболизм. - 2018. - T.15. - No. 4 - C. 65-73. doi: 10.14341/OMET10022

\section{TO CITE THIS ARTICLE:}

Shestakova EA, Stavrovskaya AV, Gushchina AS, Yamshikova NG, Olshansky AS. Cognitive function and metabolic features in male Sprague-Dawley rats receiving high-fat and low-calorie diets. Obesity and metabolism. 2018;15(4): 65-73. doi: 10.14341/OMET10022 